\title{
Identification and Evaluation of the Influencing Factors in Target Value Design Process through an Industry Survey
}

\author{
Yong-Woo Kim*, Israa Alseadi \\ University of Washington, Seattle, WA, USA \\ E-mail: yongkim@uw.edu (Corresponding Author)
}

Received: 9 December 2020; Accepted: 3 February 2021; Available online: 5 March 2021

\begin{abstract}
Target value design is a new practice in the construction industry promoting concurrent engineering and collaborative design. This paper shows the results of literature survey to identify the influencing factors in the target value design. The paper also presents the results of a questionnaire survey to explore the industry practitioners' perception of the relative importance of the influencing factors. Project stakeholders participating in the survey consider the integration of different project stakeholders in the design phase as critical. The project definition is also regarded as essential in implementing the target value design. However, the market conditions and project attributes are considered as least significant in the target value design process.
\end{abstract}

Keywords: Target costing; Target value design; Influencing factors; Survey; Integration; Project definition.

\section{Introduction}

The construction industry globally has been viewed as highly inefficient. Most construction projects suffer from low productivity compared to production systems in other sectors. Industry experts have proposed innovation in various areas of industry's traditional practices in cost reduction [1]. A central concern of any organization is how to reduce project costs while improving productivity. However, cost reduction must be accomplished without impacting the ability of the organization to achieve its long-term goals. The real issue is how to manage the cost and reduce unnecessary cost [2].

Decisions made in a design phase influence project cost more than those in a production phase. In this regard, there are many cost reduction efforts in a design phase. Chief among them is the use of target costing (TC) techniques to ensure that the product is initially designed to have a sufficient profit [3]. In Japan, about $15 \%$ of the construction projects have adopted target costing for their cost planning and management. In the construction industry, target costing research has been carried out within the framework of lean construction as target value design (TVD) method [4]. Many research reports show that projects can achieve an average cost reduction of $15 \%$ if target value design is being applied systematically to the projects [5].

In the construction industry, target value design considers that the final cost is a design parameter driving product and process design while it is regarded as an outcome of the design process in the traditional design process [6]. In target value design, associated stakeholders including specialty contractors are involved in early design to develop target cost and determine design variables from the beginning of design phase. A target value design team could estimate costs for design alternatives while ensuring not to exceed the target cost. The team should be able to use different skills to maintain the target cost without impacting on the quality and the function of the project [7].

The review of the literature on target value design reveals that no formal study on the influencing factors is available to guide the process of target value design. In this regard, the goal of this study is to investigate the influencing factors in a target value design process.

\section{Literature review}

\subsection{Target Costing (TC)}

Target costing (TC) was initially developed in Japan after the first oil crisis in 1972. Since then the process of target costing has been improved and adapted [8]. Target costing aims to reduce the overall cost of products over the entire life-cycle making sure that product quality and reliability are guaranteed. Therefore, target costing controls the product attributes and respective production processes. Target costing can be efficiently implemented by controlling the design process through defining and analyzing different production-based on engineering-driven 
alternatives. This analysis is denoted as Value Engineering (VE) and considered as a crucial part of the target costing process [9].

A study from Langfield-Smith asserted that target costing is prevalent in the manufacturing industry, not in other sectors [10]. Langfield-Smith [10] reviewed the diffusion of strategic target costing techniques over the past twenty-five years. The study [10] suggested that it would be useful to understand how target costing techniques are diffused into organizational processes.

Kato et al. [11] found that many corporations estimated costs in the product design phase. Since the initial successful application of target costing to a building project [6], the interest of using target costing methods in design phase has grown in the construction industry. Target costing has been renamed as target value design (TVD) when target costing was applied to the construction industry.

\subsection{Target Value Design (TVD)}

Traditional design and cost estimating process in the construction industry are sequential. A designer initially designs a facility and estimates it later. The sequential process results in non-value adding activities through negative iterations [4]. All too often, the project scope has to be altered to meet the project's budget. These iterations keep designers from delivering value to a customer while meeting the owner's requirements. Furthermore, the negative iterations create significant delay and waste.

In contrast, the application of target costing, which refers to 'design to target cost,' to design process enables a project team to develop the design outcomes that meet the project's budget (i.e., 'allowable cost'). Therefore, target value design helps a team avoid going over budget while delivering the features of a building that provides value to the owner. Since its inception, target value design has allowed multiple institutional projects to be completed on or below budget while adding value delivery to the customer $[6,12,13]$. As for their cost performance, a number of projects where target value design was explicitly applied have reported two persistent outcomes [14]: (1) The projects were completed below market cost, and (2) the estimated costs tend to decline as designs are developed.

\subsection{Benefits and barriers}

The use of target value design in the construction industry imposes many advantages that project stakeholders can benefit. Target value design is a management system focusing on cost reduction [11]. It also promotes the team spirit and collaborative attitude among competitors (owners and contractors) in construction projects. To efficiently implement target value design, companies should be able to overcome silo-minds and internal boundaries that each stakeholder set. Target value design is also a managerial practice which helps increase the speed of knowledge transfer and propel organizational changes by creating a culture of continuous improvement as well as enhancing employee awareness and empowerment.

Although the adoption of target value design promotes numerous benefits in the industry, there are still barriers and challenges. The main problem for target value design is that the construction industry is a limited competitive market. In other words, an exclusive market is not willing to use target costing that leverages market competitiveness [15]. According to Costa and Formoso [16], the construction industry has barriers that prevent the industry from adopting target value design as follows:

(1) construction is a project-oriented industry, and each project is unique in terms of project team and design;

(2) there are no clear guidelines in how project teams execute the process of target value design;

(3) every construction project is run by a different management team.

\section{Literature survey on factors influencing the successful implementation of TVD}

The study aims to analyze the target value design influencing factors through in-depth literature review. A comprehensive review of literature in the field was conducted with a view to identifying the factors affecting on the target value design process. The literature review found that there are thirty-two factors in five categories that impact on the target value design process.

\subsection{Category 1. Market competition}

Market condition is characterized by politics, law, economics, sociology, and technology [17]. Contractors have to maintain a long-term coordinated interaction with the local market and their competitors. The category of market competition includes five factors: the competitiveness of the construction market (V1) [17], social demand of the project type (V2) [18], the availability of reference project cost data (V3) [6], the availability of a reliable cost data (V4), and the availability of A/E and contractors capable of target value design process (V5).

These factors help determine the attributes of information on the competitors in the market analysis. These factors constitute a set of external determinants for contractors to consider in determining target costs on target pricing practices [17]. 


\subsection{Category 2. Customer's attributes}

This category of factors addresses the involvement of project owners in the target value design process. There are seven factors that represent the attributes of a customer influencing on the target value design process: plan on the customers of future projects (V6), experiences of similar target value design projects (V7), robustness of project requirements (V8), ability to define project requirements clearly in early design stage (V9), reasonable project requirement (V10) [24] , and timely responsiveness to requests from project stakeholders (V11).

\subsection{Category 3. Means}

This category of factors represents the project management tools that project stakeholders use to manage the target value design process. This category has six factors: BIM and simulations' tools (V12), process management tools such as the Last Planner System (V13), value engineering (V14), the use of decision-making tool such as Choose-by-Advantage (V15), risk management process (V16), and contractual arrangement for profit and risk sharing (V17).

\subsection{Category 4. Project characteristics}

This category of factors represents the characteristics of the project that is influencing the target costing process. The attributes of projects determine the level of uncertainty and the role of stakeholders which eventually play essential roles in the practices of a target value design project $[18,19]$. There are five factors in this category: project complexity (V18), project size (V19), the level of uncertainty and degrees of risk (V20), project delivery method (V21), and project contract method (V22).

Table 1. Factors and their Variables Influencing on TVD Process

\begin{tabular}{ll}
\hline Category 1. Market Competition \\
\hline V1 & Competitiveness of the construction market \\
V2 & Social demand of the project types \\
V3 & Availability of benchmark data for target price \\
V4 & Availability of reliable project cost data. \\
V5 & Availability of qualified A/E and contractors \\
\hline Category 2. Attributes of Customer \\
\hline V6 & Prospect of future projects \\
V7 & Experiences of similar TVD projects \\
V8 & Robustness of project requirements \\
V9 & Ability of define project requirements in early design \\
V10 & Reasonable project requirement \\
V11 & Timely Response to requests from A/E or contractors \\
\hline Category 3. Means \\
\hline V12 & Technology tools such as BIM and simulations \\
V13 & Process management tools such as LPS (Last Planner) \\
V14 & Value engineering (VE) \\
V15 & Decision making tools such as CBA (Choose-by-Advantages) \\
V16 & Risk management process \\
V17 & Contractual arrangement for profit/risk sharing \\
\hline Category 4. Project Characteristics \\
\hline V18 & Project complexity \\
V19 & Project size \\
V20 & The level of uncertainty \\
V21 & Project delivery method (DB, GCCM, DBB, and IPD) \\
V22 & Project contract method (Lumpsum, GMP, and Unit Price) \\
\hline Category 5. Process and Culture \\
\hline V23 & Degree of innovation \\
V24 & Degree of early involvement of project stakeholders \\
V25 & Level of stakeholders' commitments \\
V26 & Cultural alignment of team organization \\
V27 & Mutual respect \\
V28 & Trust \\
V29 & Stakeholder's relation and degree of cooperation \\
V30 & Timely communication among stakeholders \\
V31 & Develop parametric estimate \\
V32 & Allowing time for feedback before commitment \\
\hline
\end{tabular}




\subsection{Category 5. Process and culture}

Literature suggests that the process and organizational culture influence the successful implementation of target value design $[14,20]$. The category of process and culture has 14 factors: the degree of innovation (V23), the early involvement of project parties (V24), the level of stakeholders' commitments to target value design (V25), cultural alignment of team organization (V26), mutual respect (V27), trust (V28), stakeholder's relation and degree of cooperation (V29), timely communication among stakeholders (V30), accurate and conceptual estimate (V31), and allowing time for feedback before commitment (V32).

The full list and its source of each factor in five categories influencing the successful implementation of the target value design process are shown in Tables 1 and 2.

Table 2. The source of each Factor

\begin{tabular}{|c|c|c|c|c|c|c|}
\hline & $\begin{array}{l}\text { Cooper and } \\
\text { Slagmulder } \\
1997\end{array}$ & $\begin{array}{l}\text { Azari and Kim } \\
2016\end{array}$ & Lai et al. 2008 & $\begin{array}{l}\text { Drew and } \\
\text { Skitmore } 1992\end{array}$ & $\begin{array}{l}\text { Ballard and } \\
\text { Reiser } 2004\end{array}$ & $\begin{array}{l}\text { Tommelein } \\
\text { et al } 2011\end{array}$ \\
\hline \multicolumn{7}{|c|}{ Category 1. Market Competition } \\
\hline V1 & $\mathrm{x}$ & & & & & \\
\hline V2 & & & & $\mathrm{x}$ & & \\
\hline V3 & & & & & $\mathrm{x}$ & \\
\hline V4 & $\mathrm{x}$ & & & & & \\
\hline V5 & & & & & $\mathrm{x}$ & \\
\hline \multicolumn{7}{|c|}{ Category 2. Attributes of Customer } \\
\hline V6 & & $\bar{x}$ & & & & \\
\hline V7 & & $\mathrm{x}$ & & & & \\
\hline V8 & & $\mathrm{x}$ & & & & \\
\hline V9 & & & & & $\mathrm{x}$ & \\
\hline V10 & & & $\mathrm{x}$ & & & \\
\hline V11 & & $\mathrm{x}$ & & & & \\
\hline \multicolumn{7}{|c|}{ Category 3. Means } \\
\hline V12 & & & & & $\mathrm{x}$ & \\
\hline V13 & & & & & $\mathrm{x}$ & \\
\hline V14 & & & & & & $\mathrm{x}$ \\
\hline V15 & & & & & & $\mathrm{x}$ \\
\hline V16 & & & & & & $\mathrm{x}$ \\
\hline V17 & & & & & $\mathrm{x}$ & \\
\hline \multicolumn{7}{|c|}{ Category 4. Project Characteristics } \\
\hline V18 & & & & $\mathrm{x}$ & & \\
\hline V19 & & & & $\mathrm{x}$ & & \\
\hline V20 & & & & & & $\mathrm{x}$ \\
\hline V21 & & $\mathrm{x}$ & & & & \\
\hline V22 & & & & & & $\mathrm{x}$ \\
\hline \multicolumn{7}{|c|}{ Category 5. Process and Culture } \\
\hline V23 & & $\mathrm{x}$ & & & & \\
\hline V24 & & $\mathrm{x}$ & & & & \\
\hline V25 & $\mathrm{x}$ & & & & & \\
\hline V26 & & $\mathrm{x}$ & & & & \\
\hline V27 & & & & & & $\mathrm{x}$ \\
\hline V28 & & $\mathrm{x}$ & & & & \\
\hline V29 & & $\mathrm{x}$ & & & & \\
\hline V30 & & $\mathrm{x}$ & & & & \\
\hline V31 & & & & & & $\mathrm{x}$ \\
\hline V32 & & & $\mathrm{x}$ & & & \\
\hline
\end{tabular}




\section{Identifying Critical Factors through Survey}

\subsection{Questionnaire design and data collection}

Survey research, particularly a questionnaire survey, collects data from a sample through a cross-sectional or longitudinal study with the objective of generalizing the results of the analysis to a larger population [21]. This type of research provides a quantitative portrayal of the trends or opinions of a community through studying a sample of that population [22].

To identify critical influencing factors on the successful implementation of target value design, we used the survey as a data collection method. The questionnaires for the survey were developed based on the factors identified through literature review. Those factors have potential impacts on the target value design process as well as the outcome of target value design. The questionnaires were piloted with two senior professionals to review the list for the accuracy.

The 32 factors were addressed in a questionnaire format for the survey. The questionnaire requests that a respondent judge the importance level of each variable on a predefined five-point Likert scale $(5=$ extremely important, 4 = important, 3 = neutral, 2 = unimportant, 1 = extremely unimportant). The survey request was distributed to 78 professionals who have experienced target value design process through an online survey tool. 26 responses were collected over a two-month period. The response rate is $33.33 \%$.

Table 3 presents the role breakdown of each of the 26 respondents. Contractors made up the majority of the respondents, followed by designers and owners' representatives.

\begin{tabular}{lcc} 
Table 3. Distribution of Questionnaire Response by Respondent Role \\
\hline Respondent Role & \# of Participants & Percentage \\
\hline General Contractor & 11 & $42 \%$ \\
MEP Contractor & 2 & $8 \%$ \\
Owner's Rep & 6 & $23 \%$ \\
Architect/Engineers & 7 & $27 \%$ \\
\hline Total & 26 & $100 \%$ \\
\hline
\end{tabular}

\subsection{Descriptive statistics}

The questionnaire collected information on the level of influence of each factor on the target value design process. Descriptive statistics for the variables in the questionnaire survey (including sample size, mean, standard deviation, minimum, and maximum) are presented in Table 4.

\subsection{Reliability of the influencing factors}

The validity of survey data involves the consistency and repeatability of results using the same observations [21]. Although there are various measures of reliability assessment, internal consistency using Cronbach's Alpha is the most widely accepted measure [22].

Cronbach's coefficient alpha was employed to assess internal consistency of the scales under the headings of the influencing factors. In other words, the reliability of any given measurement refers to the extent to which it is a consistent measure of a concept, and Cronbach's alpha is one way of measuring the strength of that consistency $[22,23]$.

Table 5 shows the overall Cronbach's coefficient alpha on the data while Table 6 shows the Cronbach's alpha if each factor is deleted. Tables 5 and 6 provide evidence that all the factors had high internal consistency and considered reliable.

\subsection{Rankings of the influencing factors}

This section focuses on the ranking of the influencing factors. The ranking of the influencing factors was carried out based on their mean values. Table 7 shows the ranking of the influencing factors with the category information; Table 8 shows the ranking of the categories.

As shown in Table 7, all the mean values except two factors (V2 and V19) are more than 3.0, which suggest that most influencing factors identified through literature are regarded as essential in implementing the target value design process by all groups. Due to lack of responses or the sample size, the analysis by each stakeholder group has not been done.

From Table 8, an apparent finding is that the categories of customer attributes and process and culture were usually regarded critical among five categories. On the other hand, the categories of market condition and project characteristics are considered less critical in implementing the target value design process. The reasons why market competition and project characteristics are ranked low in this survey may include two issues. The first issue is that customer's demands are reflected in customers' attributes. The second issue is that most target value design process 
begins in schematic design phase rather than in business planning. Therefore, most procurement processes of selecting major stakeholders are completed before the target value design process launches.

Table 4. Descriptive Statistics

\begin{tabular}{lccccc}
\hline & $\mathrm{N}$ & Minimum & Maximum & Mean & $\begin{array}{c}\text { Std. } \\
\text { Deviation }\end{array}$ \\
\hline V1 & 26 & 2 & 5 & 3.5769 & 0.70274 \\
V2 & 26 & 1 & 3 & 2.5385 & 0.58177 \\
V3 & 26 & 2 & 4 & 3.2308 & 0.51441 \\
V4 & 26 & 2 & 4 & 3.1154 & 0.43146 \\
V5 & 26 & 3 & 4 & 3.4615 & 0.50839 \\
V6 & 26 & 3 & 4 & 3.5769 & 0.50383 \\
V7 & 26 & 3 & 4 & 3.6923 & 0.47068 \\
V8 & 26 & 4 & 5 & 4.4231 & 0.50383 \\
V9 & 26 & 3 & 5 & 4.0769 & 0.56022 \\
V10 & 26 & 3 & 4 & 3.5 & 0.5099 \\
V11 & 26 & 4 & 5 & 4.3462 & 0.48516 \\
V12 & 26 & 3 & 4 & 3.7692 & 0.42967 \\
V13 & 26 & 3 & 4 & 3.3077 & 0.47068 \\
V14 & 26 & 3 & 4 & 3.6923 & 0.47068 \\
V15 & 26 & 3 & 4 & 3.4231 & 0.50383 \\
V16 & 26 & 2 & 4 & 3 & 0.4 \\
V17 & 26 & 3 & 4 & 3.3846 & 0.49614 \\
V18 & 26 & 3 & 4 & 3.3077 & 0.47068 \\
V19 & 26 & 1 & 3 & 2.0769 & 0.48358 \\
V20 & 26 & 3 & 4 & 3.3462 & 0.48516 \\
V21 & 26 & 3 & 4 & 3.5769 & 0.50383 \\
V22 & 26 & 3 & 5 & 3.6923 & 0.61769 \\
V23 & 26 & 3 & 5 & 3.8077 & 0.49147 \\
V24 & 26 & 3 & 5 & 4.2692 & 0.66679 \\
V25 & 26 & 3 & 4 & 3.8846 & 0.32581 \\
V26 & 26 & 3 & 5 & 3.9615 & 0.66216 \\
V27 & 26 & 3 & 5 & 3.7308 & 0.60383 \\
V28 & 26 & 3 & 5 & 3.9231 & 0.56022 \\
V29 & 26 & 4 & 5 & 4.6538 & 0.48516 \\
V30 & 26 & 3 & 4 & 3.5769 & 0.50383 \\
V31 & 26 & 3 & 5 & 4.1154 & 0.5159 \\
V32 & 26 & 3 & 4 & 3.4231 & 0.50383 \\
\hline & & & &
\end{tabular}

Table 5. Cronbach's Alpha on all factors

\begin{tabular}{ccc}
\hline Cronbach's Alpha & Cronbach's Alpha Based on Standardized Items & No. of Items \\
\hline 0.707 & 0.699 & 32 \\
\hline
\end{tabular}

Table 6. Cronbach's Alpha if each factor is deleted

\begin{tabular}{lcccccccccccc}
\hline & V1 & V2 & V3 & V4 & V5 & V6 & V7 & V8 & V9 & V10 & V11 & V12 \\
\hline $\begin{array}{l}\text { Cronbach's Alpha if } \\
\text { each factor is } \\
\text { deleted }\end{array}$ & 0.72 & 0.7 & 0.7 & 0.71 & 0.73 & 0.68 & 0.73 & 0.7 & 0.69 & 0.69 & 0.71 & 0.68 \\
\hline & V13 & V14 & V15 & V16 & V17 & V18 & V19 & V20 & V21 & V22 & V23 & V24 \\
\hline $\begin{array}{l}\text { Cronbach's Alpha if } \\
\begin{array}{l}\text { each factor is } \\
\text { deleted }\end{array}\end{array}$ & 0.7 & 0.69 & 0.7 & 0.71 & 0.7 & 0.69 & 0.7 & 0.71 & 0.71 & 0.7 & 0.7 & 0.67 \\
\hline & V25 & V26 & V27 & V28 & V29 & V30 & V31 & V32 & & & & \\
\hline $\begin{array}{l}\text { Cronbach's Alpha if } \\
\text { each factor is } \\
\text { deleted }\end{array}$ & 0.7 & 0.67 & 0.68 & 0.72 & 0.71 & 0.7 & 0.68 & 0.71 & & & \\
\hline
\end{tabular}


Table 7. The ranking, the Influencing Factors

\begin{tabular}{|c|c|c|c|c|}
\hline Ranking & & Factor & Category & Mean \\
\hline 1 & V29 & Stakeholder's relation and degree of cooperation & Process and Culture & 4.654 \\
\hline 2 & V8 & Robustness of project requirements & Customer Attributes & 4.423 \\
\hline 3 & V11 & Timely response (owner) & Customer Attributes & 4.346 \\
\hline 4 & V24 & Degree of early involvement of project stakeholders & Process and Culture & 4.269 \\
\hline 5 & V31 & Developing parametric estimate & Process and Culture & 4.115 \\
\hline 6 & V9 & Ability to define project requirements in early design & Customer Attributes & 4.077 \\
\hline 7 & V26 & Cultural alignment of team organization & Process and Culture & 3.962 \\
\hline 8 & V28 & Trust & Process and Culture & 3.923 \\
\hline 9 & V25 & Level of stakeholders' commitments & Process and Culture & 3.885 \\
\hline 10 & V23 & Degree of innovation & Process and Culture & 3.808 \\
\hline 11 & V12 & Technology tools such as BIM and simulations & Means & 3.769 \\
\hline 12 & V27 & Mutual respect & Process and Culture & 3.731 \\
\hline 13 & V7 & Experiences of similar TVD projects & Process and Culture & 3.692 \\
\hline 14 & V14 & Value engineering (VE) & Means & 3.692 \\
\hline 15 & V22 & Project contract method (L/S, Unit Price, GMP) & Project Characteristics & 3.692 \\
\hline 16 & V1 & Competitiveness of the construction market & Market Conditions & 3.577 \\
\hline 17 & V6 & Prospect of future projects & Market Conditions & 3.577 \\
\hline 18 & V21 & Project delivery method (DB, GCCM, DBB, and IPD) & Project Characteristics & 3.577 \\
\hline 19 & V30 & Timely communication among stakeholders & Process and Culture & 3.577 \\
\hline 20 & V10 & Reasonable project requirement & Customer Attributes & 3.500 \\
\hline 21 & V5 & Availability of qualified $\mathrm{A} / \mathrm{E}$ and contractors & Market Conditions & 3.462 \\
\hline 22 & V15 & $\begin{array}{l}\text { Decision making tools such as CBA (Choose-by- } \\
\text { Advantages) }\end{array}$ & Means & 3.423 \\
\hline 23 & V32 & Allowing time for feedback before commitment & Process and Culture & 3.423 \\
\hline 24 & V17 & Contractual arrangement for profit/risk sharing & Means & 3.385 \\
\hline 25 & V20 & The level of uncertainty & Project Characteristics & 3.346 \\
\hline 26 & V13 & Process management tools such as LPS (Last Planner) & Means & 3.308 \\
\hline 27 & V18 & Project complexity & Project Characteristics & 3.308 \\
\hline 28 & V3 & Availability of benchmark data for target price & Market Conditions & 3.231 \\
\hline 29 & V4 & Availability of reliable project cost data & Market Conditions & 3.115 \\
\hline 30 & V16 & Risk management process & Means & 3.000 \\
\hline 31 & V2 & Social demand of the project types & Market Conditions & 2.539 \\
\hline 32 & V19 & Project size & Project Characteristics & 2.077 \\
\hline
\end{tabular}

Table 8. Category Ranking

\begin{tabular}{lccc}
\multicolumn{1}{c}{ Category } & Mean Value & Stand. Dev. & Ranking \\
\hline 1. Market Competition & 3.185 & 0.405 & 4 \\
2. Customer Attributes & 3.935 & 0.411 & 1 \\
3. Means & 3.436 & 0.263 & 3 \\
4. Project Characteristics & 3.179 & 0.642 & 5 \\
5. Process and Culture & 3.900 & 0.365 & 2 \\
\hline
\end{tabular}

From Table 7, factor 29 of “Stakeholder's relation and the degree of cooperation among stakeholders” was ranked the highest among all factors. This means that most survey participants who carried out the target value design process consider this factor as the most critical factor for the successful target value design process. In addition to factor 29, factors 24 (Degree of early involvement of project stakeholders, ranked 4th), 26 (Cultural alignment of team organization, ranked 7th), and 28 (Trust, ranked 8th) are the components required for project integration. The result is in line with the research outcomes on integrated project delivery process [20]. Azari and Kim [20] carried out their survey on integrated design process in which the cooperation and mutual trust are critical to the success of integrated design process.

It is also notable that the respondents have highly ranked factors 8 (Robustness of project requirements, ranked 2nd), 11 (Owner's timely response, ranked 3rd), and 9 (Ability to define project requirements in early design, ranked 6th). These factors are related to the owner's project definition, which is in line with the findings in the literature on design-build. Schaufelberger et al. [25] claim that the project definition by a project owner is one of the most critical success factors in design-build projects, which also promote concurrent engineering where the process design is carried out concurrently with the product design. 
However, factors 19 (Project size, ranked 32th), 2 (Social demands of the project type, ranked 31st), and other factors in the category of market conditions or project characteristics are considered not significant compared to other factors. Most respondents rated them low. This reflects the view that market conditions or project attributes do not make a substantial impact on the target value design process.

\section{Conclusions}

Target value design is a new practice in the construction industry promoting concurrent engineering and collaborative design. The method is new and contradicts against the traditional way of design development in which each stakeholder (e.g., designers and contractors) work in a sequential and fragmented way as opposed to collaborative and integrated approach. As a result, many owners and service providers (i.e., designers and contractors) are concerned over the process and possible challenges.

Few studies appear to have undertaken the task of investigating the influencing factors in the target value design process. This paper shows the results of literature survey to identify the influencing factors in the target value design. The paper also presents the results of a questionnaire survey to explore the industry practitioners' perception of the relative importance of the influencing factors.

A total of 32 influencing factors were identified and synthesized in the survey, which was shown to be reliable based on Cronbach's coefficient alpha values. Data were collected from various stakeholders who went through the target value design process in their past projects. Since the target value design is not prevalent in the construction market, the number of respondents participating in the survey was only 26, which restricts the scope of statistical analysis.

Findings from the analysis suggest that most influencing factors identified in the literature survey are regarded as important in carrying out the target value design. Project stakeholders participating in the survey consider the integration of different project stakeholders in the design phase as critical. The project definition is also regarded as critical in implementing the target value design. The results suggest that the customer's demands are clearly defined and fully communicated with a team of target value design including designers and contractors from the beginning of the target value design process. However, the market conditions and project attributes are considered as least significant in the target value design process.

Overall, the results reflect that the organizational integration, as well as project owners' early project definition, are most important while market conditions and project characteristics are not considered critical. These findings should be useful to construction practitioners and project owners when they undertake the target value design in their projects.

\section{Acknowledgments}

The work described in this paper was supported by P. D. Koon Endowed Fund. Special gratitude is also extended to those industry practitioners who have responded to and contributed their valuable input in completing the questionnaire.

\section{References}

[1] De Melo RS, Kaushik AD, Koskela L, Tzortzopoulos P, Granja A, Keraminiyage K. Target costing in construction: A comparative study. 22nd Annual Conference of the International Group for Lean Construction: Understanding and Improving Project Based Production. 2014. p.183-194.

[2] Steven M. Cost reduction analysis: tools and strategies. John Wiley \& Sons, New York, NY. 2010.

[3] Yazdifar H, Askarany D. A comparative study of the adoption and implementation of target costing in the UK, Australia and New Zealand. International Journal of Production Economics. 2012;135(1):382-392.

[4] Ballard G. Lean Project Delivery System. White Paper 8, Lean Construction Institute. 2000. http://www. leanconstruction.org/pdf/WP8-LPDS.pdf.

[5] Zimina D, Ballard G, Pasquire C. Target value design: using collaboration and a lean approach to reduce construction cost. Construction Management and Economics. 2012;30(5):383-398.

[6] Ballard G, Reiser P. The St. Olaf College fieldhouse project: A case study in designing to target cost. Proceedings of the 12th Annual Conference of the International Group for Lean Construction (IGLC 12). Elsinore, Denmark. 2004. p.234-249.

[7] Macomber H, Howell G, Barberio J. Target-value design: nine foundational practices for delivering surprising client value. Practice Management Digest, the American Institute of Architects (AIA). Washington, DC. 2007.

[8] Sakurai M. Target costing and how to use it. Journal Cost Management. 1989; 3(2): 39-50.

[9] Agndal H, Nilsson U. Inter-organizational cost management in the exchange process. Management Accounting Research. 2009; 20(2): 85-101. 
[10] Langfield-Smith K. Strategic MA: how far have we come in 25 years? Accounting, Auditing, and Accountability Journal. 2008; 21(2): 204-228.

[11] Kato Y, Boer G, Chow C. Target costing: An integrative management process. Journal of Cost Management. 1995; 9(1): 39.

[12] Ballard G, Rybkowski ZK. Overcoming the hurdle of first cost: action research in target costing. Proceedings of 2009 Construction Research Congress. ASCE, Seattle, WA. 2009. p.1038-1047.

[13] Ahmed S, Pasquire C, Manu E. Exploratory study of 'costing collaboratively' in the UK construction industry. In: Proc. 27th Annual Conference of the International Group for Lean Construction (IGLC). Dublin, Ireland. 2019.p.1163-1174.

[14] Tommelein I, Ballard G, Lee H. Task 4 progress report: develop target value design and delivery process to incorporate energy efficiency metrics. Report for the United States Department of Energy. University of California, Berkeley. 2011.

[15] Sharafoddin S. The utilization of target costing and its implementation method in Iran. Procedia Economics and Finance. 2012; 36: 123-127.

[16] Costa DB, Formoso CT. A set of evaluation criteria for performance measurement systems in the construction industry. Journal of Management Property Construction. 2004: 9(2): 91-102.

[17] Cooper R, Slagmulder R. Target costing and value engineering. Productivity Press, Portland.1997.

[18] Ballard G. Current benchmark for target value design. Project production systems laboratory white paper (P2SL). University of California, Berkeley, CA. 2009.

[19] Ballard G, Morris P. Maximizing owner value through target value design. AACE International Transactions. 2010; 1: 347-361.

[20] Azari R, Kim YW. Integration evaluation framework for integrated design teams of green buildings: Development and validation. Journal of Management in Engineering. 2016;32(3):04015053.

[21] Babbie E. The practice of social research (12th ed.). Belmont, CA: Wadsworth Cengage Learning. 2010.

[22] Creswell JW. Qualitative inquiry and research design: choosing among five approaches. Thousand Oaks, CA: SAGE Publications, Inc. 2012.

[23] Hinkin TR. A review of scale development practices in the study of organizations. Journal of Management. 1995; 21(5): 967-988.

[24] Lai X, Xie M, Tan KC, Yang B. Ranking of customer requirements in a competitive environment. Computers \& Industrial Engineering. 2008;54(2):202-214.

[25] Schaufelberger J, Kim Y, Han S, Jin K. The Truth of Design-Build, Bounding. Seoul, Korea.

(C) 2021 by the author(s). This work is licensed under a Creative Commons Attribution 4.0 International License (http://creativecommons.org/licenses/by/4.0/). Authors retain copyright of their work, with first publication rights granted to Tech Reviews Ltd. 